\title{
Cellular and Molecular Changes in Orthodontic Tooth Movement
}

\author{
Shahrul Hisham Zainal Ariffin, ${ }^{1}$ Zulham Yamamoto, ${ }^{1}$ Intan Zarina Zainol Abidin, ${ }^{1}$ \\ Rohaya Megat Abdul Wahab, ${ }^{2}$ and Zaidah Zainal Ariffin ${ }^{3}$ \\ ${ }^{1}$ School of Biosciences and Biotechnology, Faculty of Science and Technology, \\ Universiti Kebangsaan Malaysia, 43600 Bangi, Selangor, Malaysia \\ ${ }^{2}$ Department of Orthodontics, Faculty of Dentistry, Universiti Kebangsaan Malaysia, \\ Jalan Raja Muda Abdul Aziz, 50300 Kuala Lumpur, Malaysia \\ ${ }^{3}$ Department of Microbiology, Faculty of Applied Science, Universiti Teknologi MARA, \\ 40450 Shah Alam, Malaysia
}

Received 13 September 2011; Accepted 10 October 2011

Academic Editor: Salvatore Cuzzocrea

Tooth movement induced by orthodontic treatment can cause sequential reactions involving the periodontal tissue and alveolar bone, resulting in the release of numerous substances from the dental tissues and surrounding structures. To better understand the biological processes involved in orthodontic treatment, improve treatment, and reduce adverse side effects, several of these substances have been proposed as biomarkers. Potential biological markers can be collected from different tissue samples, and suitable sampling is important to accurately reflect biological processes. This paper covers the tissue changes that are involved during orthodontic tooth movement such as at compression region (involving osteoblasts), tension region (involving osteoclasts), dental root, and pulp tissues. Besides, the involvement of stem cells and their development towards osteoblasts and osteoclasts during orthodontic treatment have also been explained. Several possible biomarkers representing these biological changes during specific phenomenon, that is, bone remodelling (formation and resorption), inflammation, and root resorption have also been proposed. The knowledge of these biomarkers could be used in accelerating orthodontic treatment.

KEYWORDS: Orthodontic, stem cells, biomarker, bone remodelling, inflammation, root resorption

Correspondence should be addressed to Shahrul Hisham Zainal Ariffin, shahroy8@gmail.com and Rohaya Megat Abdul Wahab, rohaya@medic.ukm.my

Copyright (C) 2011 Shahrul Hisham Zainal Ariffin et al. This is an open access article distributed under the Creative Commons Attribution License, which permits unrestricted use, distribution, and reproduction in any medium, provided the original work is properly cited.

Published by TheScientificWorldJOURNAL; http://www.tswj.com/ 


\section{INTRODUCTION}

The success of orthodontic treatment is influenced by a number of factors, including periodontal health, oral hygiene, and orthodontic forces [1]. The development of new methods to accelerate orthodontic tooth movement (OTM) has been sought by clinicians as a way to shorten treatment times, reduce adverse effects such as pain, discomfort, dental caries, and periodontal diseases, and minimize iatrogenic damages such as root resorption and the subsequent development of nonvital teeth.

Tooth movement induced by orthodontic force application is characterised by remodelling changes in the dental and periodontal tissues [2]. Two interrelated processes involved in OTM are (1) deflection, or bending, of the alveolar bone and (2) remodelling of the periodontal tissues, including the dental pulp, periodontal ligament (PDL), alveolar bone, and gingiva. The applied force causes the compression of the alveolar bone and the PDL on one side, while on the opposite side the PDL is stretched [3].

When exposed to varying degrees of magnitude, frequency, and duration of mechanical loading, bone and adjacent periodontal tissues show extensive macroscopic and microscopic changes. Mechanical loading also alters periodontal tissue vascularity and blood flow, resulting in the local synthesis and release of various molecules such as neurotransmitters, cytokines, growth factors, colony-stimulating factors (cytokines that involved in maturing of various leucocyte, macrophage, and monocyte line), and arachidonic acid metabolites. The released molecules evoke cellular responses in the various cell types in and around teeth, providing a favourable microenvironment for tissue deposition or resorption [2]. Various cell-signalling pathways are activated, which ultimately stimulate PDL turnover, as well as localised bone resorption and bone deposition [4].

Orthodontic tooth movement consists of three phases: the initial phase, the lag phase, and the postlag phase. The initial phase is characterised by immediate and rapid movement and occurs 24 hours to 48 hours after the first application of force to the tooth. This rate is largely attributed to the displacement of the tooth in the PDL space. The lag phase lasts 20 to 30 days and shows relatively little to no tooth displacement. This phase is marked by PDL hyalinisation in the region of compression. No subsequent tooth movement occurs until the cells complete the removal of all of the necrotic tissues. The postlag phase follows the lag phase, during which the rate of movement increases [2].

The sequence of events following OTM can be characterized using suitable biomarkers. A biomarker is a substance that is measured and evaluated objectively as an indicator of normal biologic processes, pathogenic processes, or pharmacologic responses to a therapeutic intervention [5]. In investigating biomarkers, the rate, amount, and activity of the released substances not only reflect the activity of individual cells but also indicate the metabolic activity in the involved tissues or organs [6].

A good biomarker demonstrates high specificity and sensitivity. Specific markers are prominent only in OTM. Sensitive markers should have the ability to inform about the biological condition in terms of periodontal tissue changes and their relationships with the particular phase of OTM. Knowledge of the ongoing process can lead to proper mechanical loading and thus shorten the period of treatment, which can aid in avoiding adverse effects associated with orthodontic treatment.

This paper will discuss the tissue changes that are involved during OTM such as at compression region (involving osteoblasts), tension region (involving osteoclasts), and dental root and pulp tissues. The involvement of stem cells and their development towards osteoblasts and osteoclasts during orthodontic treatment also will be discussed in this paper. Several possible biomarkers representing these biological changes during specific phenomenon, that is, bone remodelling (formation and resorption), inflammation, and root resorption, have been identified. In this paper, we suggest several biomarkers that are involved during OTM such as ALP (bone formation) and TRAP 5a (bone resorption) which both involved in bone remodelling, LDH (inflammation), and DSPP (root resorption). The observation of these biomarkers can potentially be observed using sampling from four different sampling procedures, that is, tissue (biopsy), serum, GCF, and saliva. We propose that GCF and saliva are the best and practical sampling procedure to observe the suggested biomarkers. The knowledge of these biomarkers can be used in determining the precise force and duration that should be used for each tooth and ultimately produce optimal treatments 
with minimal side effects or accelerate the treatments. We conducted literature search by using key words such as OTM, orthodontic treatment, orthodontic markers, and orthodontic in search engine. In addition, we also manually search related literature at Universiti Kebangsaan Malaysia Library. Suitable papers and important result of the paper will be discussed and cited.

\section{TISSUE AND CELL CHANGES DURING ORTHODONTIC TOOTH MOVEMENT}

The early response of periodontal tissues to mechanical stress involves several metabolic changes that enable tooth movement. A slight change in the thickness of the PDL occurred after 1 hour of orthodontic force loading, while more significant changes were seen after 6 hours [33]. The periodontal tissues primarily affected by orthodontic forces can be divided histologically into two main regions: the compression region and tension region. Other regions that are affected are the dental root and pulp.

\subsection{Compression Region}

The compression region is an area that is pressed by the orthodontic appliance in the direction of the force. Compression results in the deformation of blood vessels and disarrangement of tissues surrounding teeth. Subsequently, blood flow and periodontal tissue changes may adapt to the compression force. Metabolic changes can occur to the cells of the periodontal ligament as a result of hypoxia and decreased nutrient levels.

In hypoxic conditions, cells will rely on anaerobic glycolysis. Many enzymes involved in an anaerobic metabolism can be potential markers. Lactate dehydrogenase is an example of a molecule that accumulates during anaerobic metabolism [34]. Cells that adapt via metabolic changes will continue to live and cells that cannot adapt to the ischaemic condition will die [35]. The dead cell will lyse, releasing all of its contents to the milieu and subsequently causing the activation of local inflammatory processes.

Mechanical forces often cause hyalinisation leading to necrosis in the PDL and lead to bone resorption. Hyalinisation occurs as cell-free areas of the PDL, in which the normal tissue architecture and staining characteristics of collagen in the processed histologic material have been lost. Distortions in the normal periodontal fibre arrangement were observed [36]. Numerous cell fragments (debris), areas of degraded matrix interspersed between the intact collagen fibrils [37], and, in some cases, pyknotic nuclei were also present in hyalinisation areas [36]. In rat models, the onset of hyalinisation of the compressed PDL was found after 24 hours of orthodontic force application. Macrophages are ultimately responsible for removing the hyalinised tissues.

Alveolar bone resorption occurs at the compression areas during tooth movement. Bone resorption occurs through osteoclastic activity by osteoclast thus creating cavity in bone known as lacunae that later will be filled in by osteoblast cells to cover the cavity. Two processes involved in bone resorption are the solubilisation of minerals and the degradation of the organ matrix, which mainly consists of type I collagen. These processes are driven by proteolytic enzymes and, in particular, matrix metalloproteinases and lysosomal cysteine proteinases [9].

According to the concept of tissue response after OTM, bone repair at the compression region only occurs when the magnitude of the force decreases [38]. However, electron microscopy observations showed that tissue repair and the formation of bone occur at the pressure areas even with the maintenance of the orthodontic forces in humans $[39,40]$. As soon as the osteoclasts become inactive and move away from the bone surface, the compression areas display bone formation [37]. Bone remodelling markers may be examined by measuring osteoclastic and osteoblastic activities at the compression regions during the early phases of OTM.

\subsection{Tension Region}

In the tension region, new bone is formed as a result of forces applied by braces during orthodontic treatment. Osteoblasts are differentiated from the local precursor cells, that is, mesenchymal stem cells. 
Mature osteoblasts form the osteoids and the mineralisation processes follow [10]. In addition, endothelial nitric oxide synthase (eNOS) was shown to mediate the bone formation in the tension area [11], which in turn suggests that eNOS could be useful markers for osteoblastic activity. Enzyme profiles have also been investigated in relation to alveolar bone formation at tension sites. Another biochemical marker that may be useful during osteoblastic activity is alkaline phosphatase (ALP) [41, 42].

\subsection{Dental Root and Pulp}

One adverse effect caused by orthodontic treatment is root resorption, which is a common iatrogenic consequence in the field of orthodontics [43] and may start during the early stages of orthodontic treatment $[44,45]$. Irreversible root resorption is caused by excessive forces or decreased resistance to normal forces. Roots do not shorten naturally with age, unless forces overcompress the PDL [44]. Some odontoclasts reside in root resorption site indicating that odontoclasts play central roles in root [9]. Study on markers involved during odontoclast activity indicates that they can be potential markers for root resorption activity.

Biomechanical treatment factors such as magnitude, duration, direction, and type of force (e.g., intermittent, interrupted, and continuous) can have an impact on root resorption [46]. In the PDL of heavily applied orthodontic rat molars, foci of lymphocytic infiltration were observed, which reflects inflammatory responses to applied orthodontic forces [15]. The discontinuation of or reductions in orthodontic forces can stop root resorption and initiate the healing process in the cementum. Intermittent forces result in shorter tooth movement distances, but they are also associated with less severe root resorption than with continuous forces. However, the relationship between the amount of tooth movement and root resorption is less clear [46], and other unknown factors may influence the extent and depth of the root resorption [43].

In rats, matrix metalloproteinase-1 (MMP-1) and cathepsin $\mathrm{K}$ are important in root resorption during tooth movement because they degrade the collagenous bone matrix in a mode similar to bone resorption [9]. MMP-1 mRNA was detected in fibroblastic cells, cementoblasts, and osteoblasts but not in odontoclasts or osteoclasts. Moreover, MMP-1 mRNA was highly expressed in some cementocytes located near odontoclasts and in many osteocytes [9]. On the other hand, cathepsin K mRNA was expressed only in odontoclasts and osteoclasts $[9,41,42]$. Other cathepsins such as cathepsin B, L, and S are expressed by osteoclasts in low amounts [9]. These indicated that MMP-1 and cathepsins warrant further observation in human as markers for tooth root resorption activity.

However, it is still difficult to find precise biomarkers for root resorption or nonvital teeth because osteoclasts are also activated. Therefore, a conventional radiograph is still a cheap, effective, and important way to monitor root resorption. However, it is not an adequate tool in the diagnosis of apical shortening, lateral or cervical root gaps, enlargement of root canals, and external root radiolucencies in early stages. It also has the limitation of being a 2-dimensional image [43, 47]. In contrast, computed tomography can also be used to evaluate root resorption using a 3-dimensional approach [43]. However, the accuracy of this approach in determining root resorption warrants further evaluation.

\section{DEVELOPMENT OF DENTAL STEM CELLS DURING OTM}

Stem cells are those with the ability to divide for indefinite periods of time and with the ability to differentiate into a variety of cell types. Stem cells can be divided into three categories: totipotent, pluripotent, and multipotent cells (Figure 1) $[48,49]$. Totipotent cells are the most primitive cells, followed by pluripotent cells. The multipotent cell type is the most differentiated type of stem cell (Figure 1) [50].

Totipotent cells have the potential to differentiate into any type of cell in the body and are capable of developing into a complete organism. After several cell division cycles, totipotent cells will develop into pluripotent cells. Pluripotent cells are capable of dividing and differentiating into any type of cell, tissue, or organ (Figure 1). However, these cells are not capable of developing into a complete organism. Multipotent cells have more limited capacities than do pluripotent cells (Figure 1). Other types of primitive cells include progenitor cells, which are able to differentiate into only one type of mature cell (Figure 1) [41, 51]. 


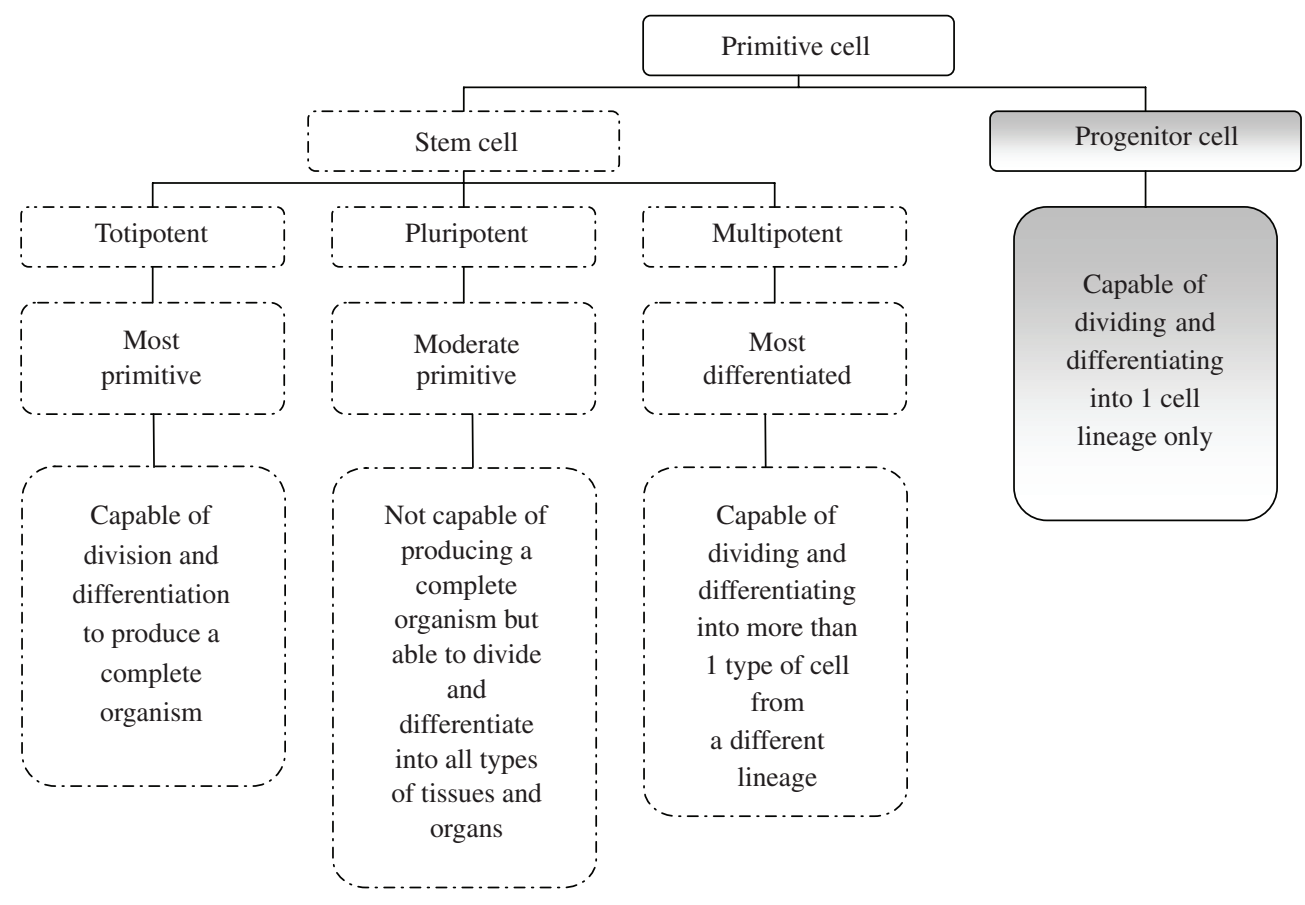

Primitive

Differentiated

FIGURE 1: Classification of primitive cells. Stem cells are primitive cells that can be classified into three types: totipotent, pluripotent, and multipotent. Each type of cell has distinguishable characteristics. The progenitor cell is also a primitive cell, although this cell is the most differentiated cell among the primitive cells.

Most stem cells are isolated from bone marrow. However, stem cells can also be found in the umbilical cord blood, peripheral blood, and teeth. Dental stem cells comprise an elusive population of self-renewing cells that may have the potential to biologically replace lost or damaged teeth in humans [52]. These cells consist of two types: epithelial stem cells and mesenchymal stem cells. Tooth formation results from the interaction of epithelial and mesenchymal stem cells, where epithelial stem cells give rise to ameloblasts and mesenchymal stem cells form odontoblasts, cementoblasts, osteoblasts, and fibroblasts of the periodontal ligament [53].

The "pressure-tension theory" associated with OTM states that the application of physiologic force, including compressional and tensional changes to the periodontal ligament (PDL), will activate mesenchymal stem cells. The PDL progenitor cells that experience force will differentiate into compressionassociated osteoclasts and tension-associated osteoblasts, causing bone resorption and apposition, respectively [7]. The multipotent mesenchymal stem cells begin their differentiation within hours of orthodontic force application [7, 54].

\subsection{Cells Involved during OTM}

Osteoblasts and osteoclasts are two important cells that are involved in OTM [7]. As such, many studies have focused on these cells during OTM. Osteoblast cells are involved in bone formation, which begins 40 to 48 hours after the application of orthodontic forces [7, 55]. Osteoblast differentiation starts with stem cells that originated from the bone marrow that migrated into the blood vessels. Migration of mesenchymal stem cells from blood vessel walls, or mesenchymal stem cell precursor activation and preosteoblast 
formation, occurs about 10 hours after the application of force [7]. This sequence of cellular activities occurs during the development of the stem cell into osteoblast and osteoclast cells may be useful in determining potential markers associated with OTM. Osteoclast cells are multinucleated cells which degrade and resorb bone. Osteoclast cells which work together with osteoblast cells in bone remodelling are derived from haematopoietic stem cells $[42,51,56]$.

\section{MARKERS FOR ORTHODONTIC TOOTH MOVEMENT}

Applying orthodontic forces to teeth will ultimately result in movement. The main phenomena, both before and after tooth movement, are alveolar bone remodelling, tissue inflammation, and root resorption. Each of these events can potentially be detected using suitable markers.

\subsection{Markers of Alveolar Bone Remodelling}

As orthodontic forces are applied to teeth, the compression region shows an elevation in osteoclastic activity. Meanwhile, in the tension region, osteoblasts begin to proliferate and mineralise the extracellular matrix. This orchestra results in alveolar bone remodelling [10].

Chemokines may contribute to differential bone remodelling in response to orthodontic forces through the establishment of distinct microenvironments in the sites of both compression and tension [57]. The principal trigger for OTM is most likely the strain experienced by the PDL cells, bone-related cells, and the extracellular matrix. This strain leads to changes in gene expression in the cells via interactions between the cells and the extracellular matrix [4]. One of the examples are matrix metalloproteinases (MMPs). MMPs break down the extracellular matrix and are important in bone remodelling. Compression induces an increase in MMP-1 protein levels after 1 hour. However, the increase lasted for 2 hours and subsequently disappeared. Tension led to significantly increased levels of MMP-1 protein after just 1 hour of force application and also subsequently disappeared [31].

MMP-2 protein was induced by compression and increased significantly in a time-dependent fashion, reaching a peak after 8 hours of force application. On the tension side, MMP-2 was significantly increased after 1 hour but gradually returned to basal levels within 8 hours [31]. This result indicates that MMP-2 could be used during very early stages of orthodontic treatment as a marker for active tooth movement.

\subsubsection{Bone Formation Marker}

Bone formation is primarily due to osteoblastic activities. Therefore, bone formation markers are usually osteoblastic enzymes or byproducts of bone formation such as type I procollagen. Type I procollagen was secreted by osteoblast cells.

The cleavages of procollagen will produce two types of procollagen, that is, procollagen type I Cterminal propeptide (PICP) and procollagen type I N-terminal propeptide (PINP) that were proposed to be measured as bone formation markers [58]. However, PICP and PINP are markers that can only indicate the formation of type I collagen and not totally bone specific [58]. Therefore, other markers that specifically activated during osteoblast differentiation or activity are needed.

Many genes are involved in osteoblast differentiation. The transcription factor (TF) Cbfa1 (or Runx2 ) is the earliest expressed and the most specific bone formation marker and helps to control osteoblast differentiation. Cbfa1-binding site also present at the regulatory sites of most genes that is involved in regulating bone matrix secretion by mature osteoblast [7]. On the other hand, Osterix, a TF, is involved in bone formation and induces mature osteoblasts to express osteocalcin. In contrast, the expression of osteocalcin will inhibit osteoblast differentiation [7, 59]. Indicate Cbfa1 and Osterix as potential markers for early and late osteoblastic activity while osteocalcin as terminal osteoblast differentiation marker.

In addition, bone morphogenetic proteins (BMPs), transforming growth factor-beta (TGF- $\beta$ ) proteins and growth-factor- (GFs) associated internal signalling molecules are other bone-forming genes that encode proteins for GFs [7]. BMPs that bind to surface receptors on progenitor and mature osteoblasts can trigger 
a signalling pathway that promotes osteoprogenitor cell differentiation and the upregulation of osteoblast activity. The expression of Cbfa1 also can be induced by BMPs.

Bone formation can also be promoted by GFs via their interaction with specific surface receptors on osteoblasts, thereby stimulating insulin-like GF-1. Insulin-like GF-1 is a primary mediator of the effects of growth hormones that have growth-promoting effects on bone, in addition to regulate cell growth and development. Other studies have found that Msx1 and Msx2 are potential regulators of bone formation. The Msx1, protein is known as a critical modulator of bone development and remodelling, and Msx2 is an alternative regulator protein of Cbfa1 expression in bone formation during OTM. Therefore, Cbfa1 (or Runx-2), osterix, osteocalcin, BMPs, TGF- $\beta$, GF-associated internal signalling, insulin-like GF-1, Msx1 and Msx2 can be used as potential biomarkers during the development of stem cells into osteoblasts during OTM.

Mechanical forces in orthodontic treatment cause the physical distortion of PDL and alveolar bone cells. They can also trigger a multilevel cascade of signal transduction pathways, such as the prostaglandin E2 $\left(\mathrm{PGE}_{2}\right)$ pathway, that initiate structural and functional changes in extracellular, cell membrane, and cytoskeletal proteins [7]. Subsequent changes in cytoskeletal protein structure and function lead to the creation of new cells and bone matrix formation [7, 60, 61].

The relationship between ALP and mineralisation has been the subject of many studies since Robinson's first discussion of the enzyme in 1923 [62]. Although extensive knowledge has been gained, the exact role of ALP in mineral formation remains to be established. Several investigations have produced consistent findings with regard to the localisation of the enzyme in mineralising tissues. Enzyme cytochemical studies have repeatedly demonstratde that ALP activity is closely associated with cell and matrix vesicle membranes in cartilage calcification, intramembranous osteogenesis, and newly forming dentine [62]. ALP activity was detected in the osteoid areas of new bone formation but not in the calcified bone matrix. The cells that showed high ALP activities were preosteoblasts, osteoblasts [41, 42, 51], lining zones, newly embedded osteocytes, endosteal cells, and subperiosteal cells [63]. In conjunction with bone formation induced by orthodontic forces, increased levels of ALP were detected in human gingival crevicular fluid (GCF) collected from orthodontically treated human samples. Therefore, they might have biological activities in the early stages of tooth movement $[17,18]$.

\subsubsection{Bone Resorption Marker}

Osteoclastic cells that are involved in bone resorption are specialised multinucleated giant cells that originate from haematopoietic stem cells $[42,64]$. The earliest bone resorption marker is the interleukin1 beta (IL-1 $\beta$ ) [7]. PGE 2 , interleukin-6 (IL-6), and other inflammatory cytokines can also facilitate osteoclastic bone resorption processes [7, 65]. These proteins regulate osteoclastic activity through activation of the nuclear factor kappa B (RANK) and of the nuclear factor kappa B ligand (RANKL). Osteoblastic cells also control osteoclastic processes by synthesizing RANKL to promote more osteoclastic differentiation $[7,66]$.

Signal induction between osteoblasts with surface expression of RANKL and osteoclastic precursors carrying the receptor RANK induces osteoclastic formation and activation [67, 68]. A study by Oshiro et al. [69] has demonstrated changes in RANK, RANKL, and osteoprotegerin (OPG) in the tooth-supporting tissues during OTM, where RANKL stimulation and OPG inhibition are involved in osteoclastogenesis $[67,70]$. Compressive forces upregulate RANKL through the $\mathrm{PGE}_{2}$ pathway and thereby support osteoclastogenesis $[67,70]$.

The transfer of the local RANKL gene to the periodontal tissue using a Hemagglutinating Virus of Japan (HVJ) envelope vector was reported to accelerate OTM in 6-week-old male Wistar rats. The activation of transferred RANKL gene in the periodontal tissue indicates that RANKL is involved during active OTM especially in periodontal area [71]. On the other hand, the activation of the OPG gene, also through gene transfer to periodontal tissues, managed to neutralize RANKL activity and hence inhibits osteoclastogenesis and eventually OTM. There is an indication that the activation of the OPG gene inhibits the OTM process [67]. Furthermore, several cases have demonstrated that increases in RANKL and decreases in OPG can be 
observed during severe orthodontic root resorption [67, 72]. Therefore, we suggest that root resorptive processes need specific biomarkers other than RANKL or OPG in order to apply optimum force during OTM.

The enzyme assay of acid phosphatase activity in saliva was also introduced as a method used to measure biomarkers of OTM. On the basis of the enzymatic profile activity of lactate dehydrogenase, tartrate resistant acid phosphatase (TRAP) and ALP in mixed saliva, Zainal Ariffin et al. [19] suggested the reactivation of orthodontic braces from 30 days to 25 days so that the treatment course will be decreased by approximately $17 \%$.

Other biomarkers of early OTM were investigated in a rat model using a split-mouth design at 3 and 24 hours after appliance insertion. The spatial expression patterns of KI-67, RANKL, and Runx2 during OTM were mapped by using immunohistochemical staining. The expression of KI-67, a proliferation marker, and RANKL, a molecule associated with osteoclastic differentiation, increased in the compression sites of the periodontal ligament subjected to 3 hours of force. On the other hand, there were increased expression of KI-67 and Runx2, both markers of osteoblastic precursors, in the areas of tension after 24 hours of force. The early expression of RANKL indicates that cells are involved in osteoclastic precursor signalling at this early stage. In addition, decreased KI-67 expression found near the midpoint of the tooth root is believed to represent the centre of rotation, providing a molecular means of visualising mechanical loading patterns and runt-related transcription factor 2 (Runx2) [12].

The potential of TRAP as a biomarker of bone resorption has been long recognised [73]. TRAP activity was very strong in in vitro osteoclast cultures. Refinement of the activity assay to primarily measure TRAP $5 \mathrm{~b}$ at a $\mathrm{pH}$ level of 6.1 was suggested for investigation of osteoclastic activity and bone resorption rates [73]. This will differentiate between TRAP 5a that have optimum $\mathrm{pH}$ at 5.2 compared to TRAP 5b with optimum $\mathrm{pH}$ at around 6 , hence TRAP5b activity can be precisely measured. However, no proper investigation has yet been conducted involving TRAP 5b assayed at a pH level of 6.1.

Nitric oxide (NO) is an important regulator of bone responses to mechanical stress and is produced through the activity of constitutive endothelial nitric oxide synthase (eNOS) or inducible nitric oxide synthase (iNOS). NO mediates adaptive bone formation, protects osteocytes against apoptosis and mediates osteoclastic activity. High levels of NO reduce osteoclastic activity, while the inhibition of NO production increases osteoclastogenesis and osteoclastic activity [11]. Using a rat model and immunohistochemistry techniques, Tan et al. [11] showed that the number of endothelial-nitric-oxide-synthase- (eNOS-) positive osteocytes was significantly higher at both 24 and 48 hours than at baseline during tooth movement. After 48 hours, however, the number decreased to baseline levels. The number of inducible-nitric-oxide-synthase(iNOS-) positive osteocytes was significantly higher than baseline levels between 6 and 48 hours, as the number increased 3.0- to 4.1-fold. Subsequently, the number decreased to baseline levels. As such, iNOS mediates inflammation-induced bone resorption in areas of compression [11].

Osteocalcin is the most abundant noncollagenous matrix protein found in bone. It is expressed by highly differentiated osteoblasts and is incorporated into the bony matrix. Smaller osteocalcin fragments are thought to be a degradation products of bone matrix, which suggests its potential as a bone resorption marker [58].

\subsection{Markers of Inflammatory Processes}

The host response to orthodontic forces has been described as aseptic and transitory inflammation. Among the substances investigated are lactate dehydrogenase (LDH) and aspartate aminotransferase (AST), which are inflammatory biomarkers found outside cells during necrosis. Increased levels of lactate dehydrogenase $[29,30]$ and aspartate aminotransferase [20-22] were detected in human GCF samples obtained during OTM. However, increased levels of lactate dehydrogenase in whole saliva can be associated with periodontal disease as well, especially with the presence of calculus and periodontal pockets greater than $5 \mathrm{~mm}$ [74]. Aspartate aminotransferase is also found in periodontitis $[75,76]$.

Cathepsin B, an intracellular lysosomal cysteine proteinase, can degrade extracellular components including collagen and cause protein turnover in the lysosomal system. It is also known to play an important 
TABLE 1: Markers involved in orthodontic tooth movement collected from dental tissues (alveolar bone, periodontium and pulp).

\begin{tabular}{|c|c|c|c|c|}
\hline Marker & Function & Sample & Method & Sources \\
\hline $\begin{array}{l}\text { Bone morphogenetic } \\
\text { proteins (BMPs) }\end{array}$ & Bone formation & Rat pulp tissue & Quantitative RT-PCR & {$[7,8]$} \\
\hline Cathepsin K & $\begin{array}{l}\text { Root and bone resorption; } \\
\text { expressed in odontoclasts and } \\
\text { osteoclasts }\end{array}$ & Rat maxillary bone & Hybridization & [9] \\
\hline $\begin{array}{l}\text { Endothelin-1, endothelin } \\
\text { receptors }\left(\mathrm{ET}_{\mathrm{A}} \text { and } \mathrm{ET}_{\mathrm{B}}\right)\end{array}$ & $\begin{array}{l}\text { Stimulates the proliferation of } \\
\text { osteoblasts; their } \\
\text { downregulation indicates the } \\
\text { end of stage } 2 \text { and start of } \\
\text { stage } 3\end{array}$ & Rat alveolar bone & RT-PCR & [10] \\
\hline $\begin{array}{l}\text { Endothelial nitric oxide } \\
\text { synthase (eNOS) }\end{array}$ & $\begin{array}{l}\text { Mediates bone formation in } \\
\text { the tension area }\end{array}$ & Rat maxilla tissue & Immunohistochemistry & [11] \\
\hline $\begin{array}{l}\text { Inducible nitric oxide } \\
\text { synthase (iNOS) }\end{array}$ & $\begin{array}{l}\text { Mediates } \\
\text { inflammation-induced bone } \\
\text { resorption in the compression } \\
\text { area. }\end{array}$ & Rat maxilla tissue & Immunohistochemistry & [11] \\
\hline Ki-67 & Proliferation & Rat maxilla & Immunohistochemistry & [12] \\
\hline $\begin{array}{l}\text { Muscle segment } \\
\text { homeobox } 1(\mathrm{Msx} 1)\end{array}$ & Regulator for bone formation & $\begin{array}{l}\text { Human alveolar } \\
\text { mucoperiosteum }\end{array}$ & $\begin{array}{l}\text { Quantitative RT-PCR, } \\
\text { Immunohistochemistry }\end{array}$ & {$[7,13]$} \\
\hline $\begin{array}{l}\text { Muscle segment } \\
\text { homeobox } 2(\mathrm{Msx} 2)\end{array}$ & Regulator for bone formation & $\begin{array}{c}\text { Mouse periodontal } \\
\text { ligament tissue }\end{array}$ & $\begin{array}{c}\text { Histopathological, } \\
\text { Immunohistochemistry }\end{array}$ & {$[7,14]$} \\
\hline Osteoprotegerin (OPG) & $\begin{array}{l}\text { Osteoclastogenesis-inhibitory } \\
\text { factor }\end{array}$ & Rat mandible & RT-PCR & [15] \\
\hline $\begin{array}{l}\text { Receptor activator of } \\
\text { nuclear factor kappa B } \\
\text { ligand (RANKL) }\end{array}$ & Osteoclastic differentiation & Rat maxilla & Immunohistochemistry & [12] \\
\hline Runx2 & Osteoblast precursor & Rat maxilla & Immunohistochemistry & {$[12]$} \\
\hline $\begin{array}{l}\text { Transforming Growth } \\
\text { Factor-B (TGF-B) }\end{array}$ & Bone formation & $\begin{array}{l}\text { Rat alveolodental } \\
\text { connective tissue }\end{array}$ & Immunohistochemistry & [7] \\
\hline
\end{tabular}

role in the initiation and perpetuation of inflammatory processes. The accumulation of cathepsin B in GCF has been shown to increase with OTM. Cathepsin B was increased around osteoclasts; it played a role in the decomposition of exposed collagen fibres and collagen degradation byproducts [23].

Myeloperoxidase (MPO) is an enzyme found in polymorphonuclear neutrophil (PMN) granules and can be used to estimate the number of PMN granules in tissues. Mean MPO activity was increased in both the GCF and saliva of orthodontic patients at 2 hours after appliance activation. MPO might be a good biomarker to assess inflammation in orthodontic movement [32].

\subsection{Markers of Root Resorption}

Root resorption is either a physiological or pathological condition associated with tooth structure loss and is caused by osteoclastic cells. Orthodontic treatment invariably results in permanent root resorption [47]. The resorptive process starts just below the gingival epithelial attachment of the tooth, extending apically and/or 
TABLE 2: Markers involved in orthodontic tooth movement collected from serum.

\begin{tabular}{lcccc}
\hline Marker & Function & Sample & Method & Sources \\
\hline $\begin{array}{l}\text { N-terminal propeptide of type 1 } \\
\text { procollagen }\end{array}$ & Bone turnover & $\begin{array}{c}\text { Serum of } \\
\text { premenopausal } \\
\text { woman }\end{array}$ & ELISA & [16] \\
\hline Osteocalcin & Bone turnover & $\begin{array}{c}\text { Serum of } \\
\text { premenopausal } \\
\text { woman }\end{array}$ & ELISA & {$[16]$} \\
\hline $\begin{array}{l}\text { C-telopeptide of type 1 collagen } \\
\text { (CTX) }\end{array}$ & Bone turnover & $\begin{array}{c}\text { Serum of } \\
\text { premenopausal } \\
\text { woman }\end{array}$ & ELISA & [16] \\
\hline Insulin-like growth factor-1 & $\begin{array}{c}\text { Decreases collagen } \\
\text { degradation, increases bone } \\
\text { matrix deposition, and } \\
\text { recruits osteoblasts }\end{array}$ & $\begin{array}{c}\text { Serum of } \\
\text { premenopausal } \\
\text { woman }\end{array}$ & ELISA & [16] \\
\hline
\end{tabular}

coronally along the root dentin. Usually, even in advanced cases, there is no pulpal involvement because of the protective nature of the predentine layer, which explains the asymptomatic nature of this type of resorption. However, the very thin dentin layer that remains is at risk of perforation during the removal of the existing granulation tissue and may necessitate root canal treatment. The often delayed nature of the resorptive process is even more difficult to explain. According to one theory, there is a decrease in the ratio of organic to inorganic cementum cells [77].

Dentine consists of noncollagenous proteins such as DMP1 (dentine matrix protein 1), dentine phosphoprotein (DPP), and dentine sialoprotein (DSP). DPP and DSP are products of mRNA transcription and are portions of one expressed protein known as dentine sialophosphoprotein (DSPP). Examination of patients undergoing active orthodontic treatment showed elevated levels of DPP relative to the control group [25]. Kereshanan et al. [26] reported the potential for measuring dentine sialoprotein (DSP) in GCF as a biomarker to monitor root resorption. GCF was collected from 20 patients undergoing treatment with fixed appliances at two time points, immediately prior to orthodontic intervention and 12 weeks following the commencement of fixed appliance therapy. GCF samples were analysed for DSP using an immunoassay and the levels were semiquantified using an image analysis. Results showed that DSP was raised at sites that were undergoing physiological resorption compared with the nonresorbing controls. Notably, however, DSP was detected in some of the control samples. Dentine is likely to be the major source for DSP in GCF, although alternative origins such as bone and cementum are possible.

The peripheral nervous system in the tooth pulp and periodontium contributes to the development of both acute and chronic inflammatory processes via the release of substance P (SP). SP stimulated the production of IL- $1 \beta$, IL- 6 , and TNF- $\alpha$ in vitro in human dental pulp fibroblasts with severe orthodontic root resorption [72].

\section{CONCLUSION}

Many papers have proposed certain substances as biomarkers of OTM. There is progress in the development of biomarkers to better understand the ongoing biological processes involved with OTM. On the basis of sequential reactions and released substances, numerous substances have been proposed as biomarkers. Knowledge regarding stem cell development and osteoblastic and osteoclastic activity involved in bone formation and resorption, respectively, can be useful in the identification of potential OTM biomarkers as well. There is also the question of how to obtain useful samples by ethical and noninvasive methods. To this 
TABLE 3: Markers involved in orthodontic tooth movement collected from GCF and saliva.

\begin{tabular}{|c|c|c|c|c|}
\hline Marker & Function & Sample & Method & Sources \\
\hline $\begin{array}{l}\text { Alkaline phosphatase } \\
\text { (ALP) }\end{array}$ & Bone formation & Human saliva and GCF & Enzyme assay & [17-19] \\
\hline $\begin{array}{l}\text { Aspartate } \\
\text { aminotransferase } \\
\text { (AST) }\end{array}$ & $\begin{array}{l}\text { Tissue damage and } \\
\text { inflammatory process }\end{array}$ & Human GCF & Enzyme assay & [20-22] \\
\hline Cathepsin B & $\begin{array}{l}\text { Resolution organic matrix; bone } \\
\text { resorption }\end{array}$ & Human GCF & $\begin{array}{l}\text { Fluorometry, } \\
\text { enzyme assay, } \\
\text { Western blot }\end{array}$ & {$[23,24]$} \\
\hline $\begin{array}{l}\text { Dentine } \\
\text { phosphoprotein (DPP) }\end{array}$ & Root resorption & Human GCF & ELISA & {$[25]$} \\
\hline $\begin{array}{l}\text { Dentine sialoprotein } \\
\text { (DSP) }\end{array}$ & Root resorption & Human GCF & Western blot & {$[26]$} \\
\hline $\begin{array}{l}\text { Activity index of } \\
\text { Interleukin- } 1 \beta \text { and } \\
\text { interleukin-1 receptor } \\
\text { antagonist }\end{array}$ & $\begin{array}{l}\mathrm{IL}-1 \beta \text { is potent for bone } \\
\text { resorption and the inhibition of } \\
\text { bone formation }\end{array}$ & Human GCF & ELISA & {$[27]$} \\
\hline Interleukin-2 (IL-2) & $\begin{array}{l}\text { B-cell activation, stimulates } \\
\text { macrophages and NK Cell, } \\
\text { T-cell proliferation, osteoclastic } \\
\text { activity }\end{array}$ & Human GCF & Immunoassay & {$[28]$} \\
\hline Interleukin-6 (IL-6) & $\begin{array}{l}\text { Stimulates osteoclast formation } \\
\text { and bone resorbing activity of } \\
\text { preformed osteoclasts }\end{array}$ & Human GCF & Immunoassay & {$[28]$} \\
\hline Interleukin-8 (IL-8) & $\begin{array}{l}\text { Recruitment and activation of } \\
\text { neutrophils }\end{array}$ & Human GCF & Immunoassay & {$[28]$} \\
\hline $\begin{array}{l}\text { Lactate dehydrogenase } \\
(\mathrm{LDH})\end{array}$ & $\begin{array}{l}\text { For monitoring periodontal } \\
\text { metabolic changes, index of } \\
\text { tissue destruction }\end{array}$ & Human saliva and GCF & Enzyme assay & $\begin{array}{c}{[19,29,} \\
30]\end{array}$ \\
\hline $\begin{array}{l}\text { Matrix } \\
\text { metalloproteinase-1 } \\
(\text { MMP-1) }\end{array}$ & $\begin{array}{l}\text { PDL remodelling during initial } \\
\text { tooth movement }\end{array}$ & Human GCF & Western blot & {$[31]$} \\
\hline $\begin{array}{l}\text { Matrix } \\
\text { metalloproteinase-2 } \\
(\text { MMP-2) }\end{array}$ & $\begin{array}{l}\text { PDL remodelling during initial } \\
\text { tooth movement }\end{array}$ & Human GCF & Western blot & {$[31]$} \\
\hline Myeloperoxidase & $\begin{array}{l}\text { To asses inflammation in } \\
\text { orthodontic movement }\end{array}$ & Human GCF & Enzyme assay & {$[32]$} \\
\hline $\begin{array}{l}\text { Tartrate resistant acid } \\
\text { phosphatase (TRAP) }\end{array}$ & Osteoclastic differentiation & Human GCF & Enzyme assay & [19] \\
\hline
\end{tabular}

end, saliva and GCF are two common, noninvasive methods of collecting samples associated with OTM. A summary of all currently known potential markers for OTM is shown in Tables 1, 2, and 3. The clinical use of these biomarkers is still an issue. Therefore, the determination of suitable OTM process biomarkers remains a challenging task. In this paper, we proposed one potential marker for each phase during OTM, that is, ALP (bone formation), TRAP5a (bone resorption), LDH (inflammation), and DSPP (root resorption). 


\section{ACKNOWLEDGMENTS}

The authors would like to thank the Ministry of Higher Education Malaysia (FRGS/1/2011/SG/UKM/02/13, and UKMDD-03-FRGS0030-2010), Ministry of Science, Technology and Innovation Malaysia (09-05MGI-GMB002), and Universiti Kebangsaan Malaysia (UKM-OUP-KPB-33-170/2011 and UKM-GUP2011-093) for the financial grants during this study.

\section{REFERENCES}

[1] D. Cardaropoli and L. Gaveglio, "The influence of orthodontic movement on periodontal tissues level," Seminars in Orthodontics, vol. 13, no. 4, pp. 234-245, 2007.

[2] V. Krishnan and Z. Davidovitch, "Cellular, molecular, and tissue-level reactions to orthodontic force," American Journal of Orthodontics and Dentofacial Orthopedics, vol. 129, no. 4, pp. 469-e1, 2006.

[3] C. Dolce, J. Scott Malone, and T. T. Wheeler, "Current concepts in the biology of orthodontic tooth movement," Seminars in Orthodontics, vol. 8, no. 1, pp. 6-12, 2002.

[4] T. Bartzela, J. C. Türp, E. Motschall, and J. C. Maltha, "Medication effects on the rate of orthodontic tooth movement: a systematic literature review," American Journal of Orthodontics and Dentofacial Orthopedics, vol. 135, no. 1, pp. 16-26, 2009.

[5] M. Taba, J. Kinney, A. S. Kim, and W. V. Giannobile, "Diagnostic biomarkers for oral and periodontal diseases," Dental Clinics of North America, vol. 49, no. 3, pp. 551-571, 2005.

[6] D. Bernardi, M. Zaninotto, and M. Plebani, "Requirements for improving quality in the measurement of bone markers," Clinica Chimica Acta, vol. 346, no. 1, pp. 79-86, 2004.

[7] R. S. Masella and M. Meister, "Current concepts in the biology of orthodontic tooth movement," American Journal of Orthodontics and Dentofacial Orthopedics, vol. 129, no. 4, pp. 458-468, 2006.

[8] Y. Enokiya, S. Hashimoto, T. Muramatsu et al., "Effect of stretching stress on gene transcription related to earlyphase differentiation in rat periodontal ligament cells," The Bulletin of Tokyo Dental College, vol. 51, no. 3, pp. 129-137, 2010.

[9] S. Domon, H. Shimokawa, Y. Matsumoto, S. Yamaguchi, and K. Soma, "In situ hybridization for matrix metalloproteinase-1 and cathepsin K in rat root-resorbing tissue induced by tooth movement," Archives of Oral Biology, vol. 44, no. 11, pp. 907-915, 1999.

[10] S. Sprogar, T. Vaupotic, A. Cör, M. Drevenšek, and G. Drevenšek, “The endothelin system mediates bone modeling in the late stage of orthodontic tooth movement in rats," Bone, vol. 43, no. 4, pp. 740-747, 2008.

[11] S. D. Tan, R. Xie, J. Klein-Nulend et al., "Orthodontic force stimulates eNOS and iNOS in rat osteocytes," Journal of Dental Research, vol. 88, no. 3, pp. 255-260, 2009.

[12] P. J. Brooks, D. Nilforoushan, M. F. Manolson, C. A. Simmons, and S. G. Gong, "Molecular markers of early orthodontic tooth movement," Angle Orthodontist, vol. 79, no. 6, pp. 1108-1113, 2009.

[13] F. Wehrhan, P. Hyckel, J. Ries et al., "Expression of Msx-1 is suppressed in bisphosphonate associated osteonecrosis related jaw tissue-etiopathology considerations respecting jaw developmental biology-related unique features," Journal of Translational Medicine, vol. 8, article no. 96, 2010.

[14] T. Watanabe, K. Nakano, R. Muraoka et al., "Role of Msx2 as a promoting factor for Runx2 at the periodontal tension sides elicited by mechanical stress," European Journal of Medical Research, vol. 13, no. 9, pp. 425-431, 2008.

[15] E. Low, H. Zoellner, O. P. Kharbanda, and M. A. Darendeliler, "Expression of mRNA for osteoprotegerin and receptor activator of nuclear factor kappa $\beta$ ligand (RANKL) during root resorption induced by the application of heavy orthodontic forces on rat molars," American Journal of Orthodontics and Dentofacial Orthopedics, vol. 128, no. 4, pp. 497-503, 2005.

[16] S. Adami, A. Zivelonghi, V. Braga et al., "Insulin-like growth factor-1 is associated with bone formation markers, PTH and bone mineral density in healthy premenopausal women," Bone, vol. 46, no. 1, pp. 244-247, 2010.

[17] G. Perinetti, M. Paolantonio, M. D’Attilio et al., "Alkaline phosphatase activity in gingival crevicular fluid during human orthodontic tooth movement," American Journal of Orthodontics and Dentofacial Orthopedics, vol. 122, no. 5, pp. 548-556, 2002. 
[18] A. A. A. Asma, R. Megat Abdul Wahab, and S. H. Zainal Ariffin, "Crevicular alkaline phosphatase activity during orthodontic tooth movement: canine retraction stage," Journal of Medical Sciences, vol. 8, no. 3, pp. 228-233, 2008.

[19] S. H. Zainal Ariffin, M. F. Ellias, R. Megat Abdul Wahab, Y. Bakar, and S. Senafi, "Profiles of lactate dehydrogenase, tartrate resistant acid phosphatase and alkaline phosphatase in saliva during orthodontic treatment," Sains Malaysiana, vol. 39, no. 3, pp. 405-412, 2010.

[20] G. Perinetti, M. Paolantonio, M. D'Attilio et al., "Aspartate aminotransferase activity in gingival crevicular fluid during orthodontic treatment. A controlled short-term longitudinal study," Journal of Periodontology, vol. 74, no. 2, pp. 145-152, 2003.

[21] R. Megat Abdul Wahab, S. H. Zainal Ariffin, and K. Khazlina, "The activity of aspartate aminotransferase during canine retraction (Bodily Tooth Movement) in orthodontic treatment," Journal of Medical Sciences, vol. 8, no. 6, pp. 553-558, 2008.

[22] R. Megat Abdul Wahab, S. H. Zainal Ariffin, and K. Khazlina, "Preliminary study of aspartate aminotransferase activity in gingival crevicular fluids during orthodontic tooth movement," Journal of Applied Sciences, vol. 9, no. 7, pp. 1393-1396, 2009.

[23] S. H. Rhee, J. Kang, and D. S. Nahm, "Cystatins and cathepsin B during orthodontic tooth movement," American Journal of Orthodontics and Dentofacial Orthopedics, vol. 135, no. 1, pp. 99-105, 2009.

[24] Y. Sugiyama, M. Yamaguchi, M. Kanekawa et al., "The level of cathepsin B in gingival crevicular fluid during human orthodontic tooth movement," European Journal of Orthodontics, vol. 25, no. 1, pp. 71-76, 2003.

[25] J. Mah and N. Prasad, "Dentine phosphoproteins in gingival crevicular fluid during root resorption," European Journal of Orthodontics, vol. 26, no. 1, pp. 25-30, 2004.

[26] S. Kereshanan, P. Stephenson, and R. Waddington, "Identification of dentine sialoprotein in gingival crevicular fluid during physiological root resorption and orthodontic tooth movement," European Journal of Orthodontics, vol. 30, no. 3, pp. 307-314, 2008.

[27] L. R. Iwasaki, J. E. Haack, J. C. Nickel, R. A. Reinhardt, and T. M. Petro, "Human interleukin-1 $\beta$ and interleukin1 receptor antagonist secretion and velocity of tooth movement," Archives of Oral Biology, vol. 46, no. 2, pp. 185-189, 2001.

[28] G. Başaran, T. Özer, F. A. Kaya, and O. Hamamci, "Interleukins 2, 6, and 8 levels in human gingival sulcus during orthodontic treatment," American Journal of Orthodontics and Dentofacial Orthopedics, vol. 130, no. 1, pp. 7.e1-7.e6, 2006.

[29] E. Serra, G. Perinetti, M. D’Attilio et al., "Lactate dehydrogenase activity in gingival crevicular fluid during orthodontic treatment," American Journal of Orthodontics and Dentofacial Orthopedics, vol. 124, no. 2, pp. 206-211, 2003.

[30] G. Perinetti, E. Serra, M. Paolantonio et al., "Lactate dehydrogenase activity in human gingival crevicular fluid during orthodontic treatment: a controlled, short-term longitudinal study," Journal of Periodontology, vol. 76, no. 3, pp. 411-417, 2005.

[31] G. Cantarella, R. Cantarella, M. Caltabiano, N. Risuglia, R. Bernardini, and R. Leonardi, "Levels of matrix metalloproteinases 1 and 2 in human gingival crevicular fluid during initial tooth movement," American Journal of Orthodontics and Dentofacial Orthopedics, vol. 130, no. 5, pp. 568-e11, 2006.

[32] A. M. Marcaccini, P. A. F. Amato, F. V. Leão, R. F. Gerlach, and J. T. L. Ferreira, "Myeloperoxidase activity is increased in gingival crevicular fluid and whole saliva after fixed orthodontic appliance activation," American Journal of Orthodontics and Dentofacial Orthopedics, vol. 138, no. 5, pp. 613-616, 2010.

[33] Y. Nakamura, K. Noda, S. Shimoda et al., "Time-lapse observation of rat periodontal ligament during function and tooth movement, using microcomputed tomography," European Journal of Orthodontics, vol. 30, no. 3, pp. 320-326, 2008.

[34] S. Passarella, L. de Bari, D. Valenti, R. Pizzuto, G. Paventi, and A. Atlante, "Mitochondria and 1-lactate metabolism," FEBS Letters, vol. 582, no. 25-26, pp. 3569-3576, 2008.

[35] Y. Kitase, M. Yokozeki, S. Fujihara et al., "Analysis of gene expression profiles in human periodontal ligament cells under hypoxia: the protective effect of CC chemokine ligand 2 to oxygen shortage," Archives of Oral Biology, vol. 54, no. 7, pp. 618-624, 2009. 
[36] M. von Böhl, J. C. Maltha, J. W. von den Hoff, and A. M. Kuijpers-Jagtman, "Focal hyalinization during experimental tooth movement in beagle dogs," American Journal of Orthodontics and Dentofacial Orthopedics, vol. 125, no. 5, pp. 615-623, 2004.

[37] L. Bonafe-Oliveira, R. M. Faltin, and V. E. Arana-Chavez, "Ultrastructural and histochemical examination of alveolar bone at the pressure areas of rat molars submitted to continuous orthodontic force," European Journal of Oral Sciences, vol. 111, no. 5, pp. 410-416, 2003.

[38] K. Reitan and P. Rygh, "Tissue reactions in orthodontics," in Orthodontics Current Principles and Techniques, T. M. Graber, R. L. Vanarsdall, and K. W. L. Vig, Eds., CV Mosby, St Louis, Mo, USA, 4th edition, 2005.

[39] R. M. Faltin, K. Faltin, F. G. Sander, and V. E. Arana-Chavez, "Ultrastructure of cementum and periodontal ligament after continuous intrusion in humans: a transmission electron microscopy study," European Journal of Orthodontics, vol. 23, no. 1, pp. 35-49, 2001.

[40] M. A. Casa, R. M. Faltin, K. Faltin, and V. E. Arana-Chavez, "Root resorption on torqued human premolars shown by tartrate-resistant acid phosphatase histochemistry and transmission electron microscopy," Angle Orthodontist, vol. 76, no. 6, pp. 1015-1021, 2006.

[41] M. D. Yazid, S. H. Zainal Ariffin, S. Senafi, M. A. Razak, and R. Megat Abdul Wahab, "Determination of the differentiation capacities of murines' primary mononucleated cells and MC3T3-E1 cells," Cancer Cell International, vol. 10, article 42, 2010.

[42] S. H. Zainal Ariffin, I. Z. Zainol Abidin, M. D. Yazid, and R. Megat Abdul Wahab, "Differentiation analyses of adult suspension mononucleated peripheral blood cells of Mus musculus," Cell Communication and Signaling, pp. 29-35, 2010.

[43] J. Kurol, P. Owman-Moll, and D. Lundgren, "Time-related root resorption after application of a controlled continuous orthodontic force," American Journal of Orthodontics and Dentofacial Orthopedics, vol. 110, no. 3, pp. 303-310, 1996.

[44] E. F. Harris, "Root resorption during orthodontic therapy," Seminars in Orthodontics, vol. 6, no. 3, pp. 183-194, 2000.

[45] I. Smale, J. Årtun, F. Behbehani, D. Doppel, M. Van’t Hof, and A. M. Kuijpers-Jagtman, “Apical root resorption 6 months after initiation of fixed orthodontic appliance therapy," American Journal of Orthodontics and Dentofacial Orthopedics, vol. 128, no. 1, pp. 57-67, 2005.

[46] T. Kumasako-Haga, T. Konoo, K. Yamaguchi, and H. Hayashi, "Effect of 8-hour intermittent orthodontic force on osteoclasts and root resorption," American Journal of Orthodontics and Dentofacial Orthopedics, vol. 135, no. 3, pp. 278-e1, 2009.

[47] C. Estrela, M. R. Bueno, A. H. G. De Alencar et al., "Method to evaluate inflammatory root resorption by using cone beam computed tomography," Journal of Endodontics, vol. 35, no. 11, pp. 1491-1497, 2009.

[48] S. H. Zainal Ariffin, R. Megat Abdul Wahab, I. Ismail, N. M. Mahadi, and Z. Zainal Ariffin, "Stem cells, cytokines and their receptors," Asia-Pacific Journal of Molecular Biology and Biotechnology, vol. 13, no. 1, pp. 1-13, 2005.

[49] N. Shanthly, M. R. Aruva, K. Zhang, B. Mathew, and M. L. Thakur, "Stem cells: a regenerative pharmaceutical," Quarterly Journal of Nuclear Medicine and Molecular Imaging, vol. 50, no. 3, pp. 205-216, 2006.

[50] S. H. Zainal Ariffin, R. Megat Abdul Wahab, I. Z. Zainol Abidin, S. Sahidan, M. M. Nor, and Z. Zainal Ariffin, "Stem cell in blood development," Sains Malaysiana, vol. 34, pp. 21-26, 2005.

[51] I. Z. Zainol Abidin, S. H. Zainal Ariffin, R. Megat Abdul Wahab, S. Sahidan, and Z. Zainal Ariffin, "Osteoclast and osteoblast development of Mus musculus haemopoietic mononucleated cells," Journal of Biological Sciences, vol. 8, no. 3, pp. 506-516, 2008.

[52] P. C. Yelick and J. P. Vacanti, "Dental stem cells," in Handbook of Stem Cells, P. Andrews, J. Cibelli, R. Edwards et al., Eds., Academic Press, Amsterdam, The Netherlands, 2004.

[53] G. Bluteau, H. U. Luder, C. De Bari, and T. A. Mitsiadis, "Stem cells for tooth engineering," European Cells and Materials, vol. 16, pp. 1-9, 2008.

[54] M. K. Sutherland, J. C. Geoghegan, C. Yu et al., "Sclerostin promotes the apoptosis of human osteoblastic cells: a novel regulation of bone formation," Bone, vol. 35, no. 4, pp. 828-835, 2004.

[55] W. E. Roberts, S. S. Huja, and J. A. Roberts, "Bone modeling: biomechanics, molecular mechanisms, and clinical perspectives," Seminars in Orthodontics, vol. 10, no. 2, pp. 123-161, 2004. 
[56] A. E. Grigoriadis, M. Kennedy, A. Bozec et al., "Directed differentiation of hematopoietic precursors and functional osteoclasts from human ES and iPS cells," Blood, vol. 115, no. 14, pp. 2769-2776, 2010.

[57] T. P. Garlet, U. Coelho, C. E. Repeke, J. S. Silva, F. D. Q. Cunha, and G. P. Garlet, "Differential expression of osteoblast and osteoclast chemmoatractants in compression and tension sides during orthodontic movement," Cytokine, vol. 42, no. 3, pp. 330-335, 2008.

[58] R. A. Hannon and R. Eastell, "Bone markers and current laboratory assays," Cancer Treatment Reviews, vol. 32, no. 1, pp. 7-14, 2006.

[59] K. S. Lee, H. J. Kim, Q. L. Li et al., "Runx2 is a common target of transforming growth factor $\beta 1$ and bone morphogenetic protein 2, and cooperation between Runx2 and Smad5 induces osteoblast-specific gene expression in the pluripotent mesenchymal precursor cell line C2C12," Molecular and Cellular Biology, vol. 20, no. 23, pp. 8783-8792, 2000.

[60] J. Parkin and B. Cohen, “An overview of the immune system," The Lancet, vol. 357, no. 9270, pp. 1777-1789, 2001.

[61] A. J. Zhu and M. P. Scott, "Incredible journey: how do developmental signals travel through tissue?" Genes and Development, vol. 18, no. 24, pp. 2985-2997, 2004.

[62] D. C. Morris, J. C. Randall, and H. C. Anderson, "Light microscopic localization of alkaline phosphatase in fetal bovine bone using immunoperoxidase and immunogold-silver staining procedures," Journal of Histochemistry \& Cytochemistry, vol. 36, no. 3, pp. 323-327, 1988.

[63] D. Miao and A. Scutt, "Histochemical localization of alkaline phosphatase activity in decalcified bone and cartilage," Journal of Histochemistry \& Cytochemistry, vol. 50, no. 3, pp. 333-340, 2002.

[64] T. Miyamoto and T. Suda, "Differentiation and function of osteoclasts," The Keio Journal of Medicine, vol. 52, no. 1, pp. 1-7, 2003.

[65] N. Alhashimi, L. Frithiof, P. Brudvik, and M. Bakhiet, "Orthodontic tooth movement and de novo synthesis of proinflammatory cytokines," American Journal of Orthodontics and Dentofacial Orthopedics, vol. 119, no. 3, pp. 307-312, 2001.

[66] G. Karsenty, "The complexities of skeletal biology," Nature, vol. 423, no. 6937, pp. 316-318, 2003.

[67] G. E. Wise and G. J. King, "Mechanisms of tooth eruption and orthodontic tooth movement," Journal of Dental Research, vol. 87, no. 5, pp. 414-434, 2008.

[68] H. Yasuda, N. Shima, N. Nakagawa et al., "A novel molecular mechanism modulating osteoclast differentiation and function," Bone, vol. 25, no. 1, pp. 109-113, 1999.

[69] T. Oshiro, A. Shiotani, Y. Shibasaki, and T. Sasaki, "Osteoclast induction in periodontal tissue during experimental movement of incisors in osteoprotegerin-deficient mice," The Anatomical Record, vol. 266, no. 4, pp. 218-225, 2002.

[70] H. Kanzaki, M. Chiba, Y. Shimizu, and H. Mitani, "Dual regulation of osteoclast differentiation by periodontal ligament cells through RANKL stimulation and OPG inhibition," Journal of Dental Research, vol. 80, no. 3, pp. 887-891, 2001.

[71] H. Kanzaki, M. Chiba, A. Sato et al., "Cyclical tensile force on periodontal ligament cells inhibits osteoclastogenesis through OPG induction," Journal of Dental Research, vol. 85, no. 5, pp. 457-462, 2006.

[72] M. Yamaguchi, Y. Ozawa, H. Mishima, N. Aihara, T. Kojima, and K. Kasai, "Substance P increases production of proinflammatory cytokines and formation of osteoclasts in dental pulp fibroblasts in patients with severe orthodontic root resorption," American Journal of Orthodontics and Dentofacial Orthopedics, vol. 133, no. 5, pp. 690-698, 2008.

[73] L. T. Yam and A. J. Janckila, “Tartrate-resistant acid phosphatase (TRACP): a personal perspective," Journal of Bone and Mineral Research, vol. 18, no. 10, pp. 1894-1896, 2003.

[74] V. A. de la Peña, P. Diz Dios, and R. Tojo Sierra, "Relationship between lactate dehydrogenase activity in saliva and oral health status," Archives of Oral Biology, vol. 52, no. 10, pp. 911-915, 2007.

[75] N. Ozmeric, "Advances in periodontal disease markers," Clinica Chimica Acta, vol. 343, no. 1-2, pp. 1-16, 2004.

[76] B. Zappacosta, A. Manni, S. Persichilli et al., "Salivary thiols and enzyme markers of cell damage in periodontal disease," Clinical Biochemistry, vol. 40, no. 9-10, pp. 661-665, 2007. 
[77] A. Smidt, E. Nuni, and D. Keinan, "Invasive cervical root resorption: treatment rationale with an interdisciplinary approach," Journal of Endodontics, vol. 33, no. 11, pp. 1383-1387, 2007.

This article should be cited as follows:

Shahrul Hisham Zainal Ariffin, Zulham Yamamoto, Intan Zarina Zainol Abidin, Rohaya Megat Abdul Wahab, and Zaidah Zainal Ariffin, "Cellular and Molecular Changes in Orthodontic Tooth Movement," TheScientificWorldJOURNAL, vol. 11, pp. 1788-1803, 2011. 


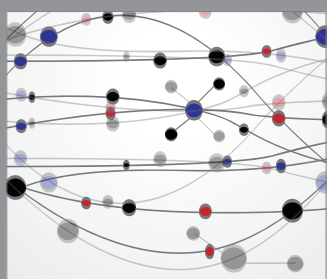

The Scientific World Journal
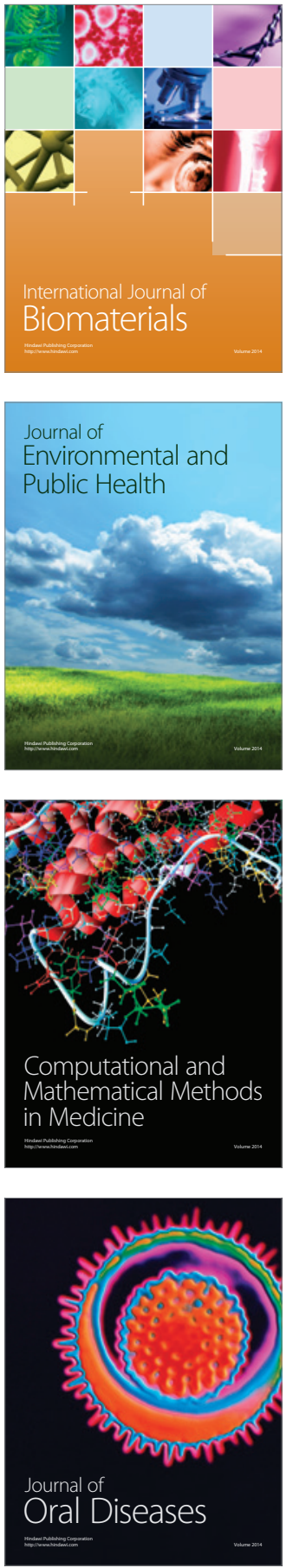
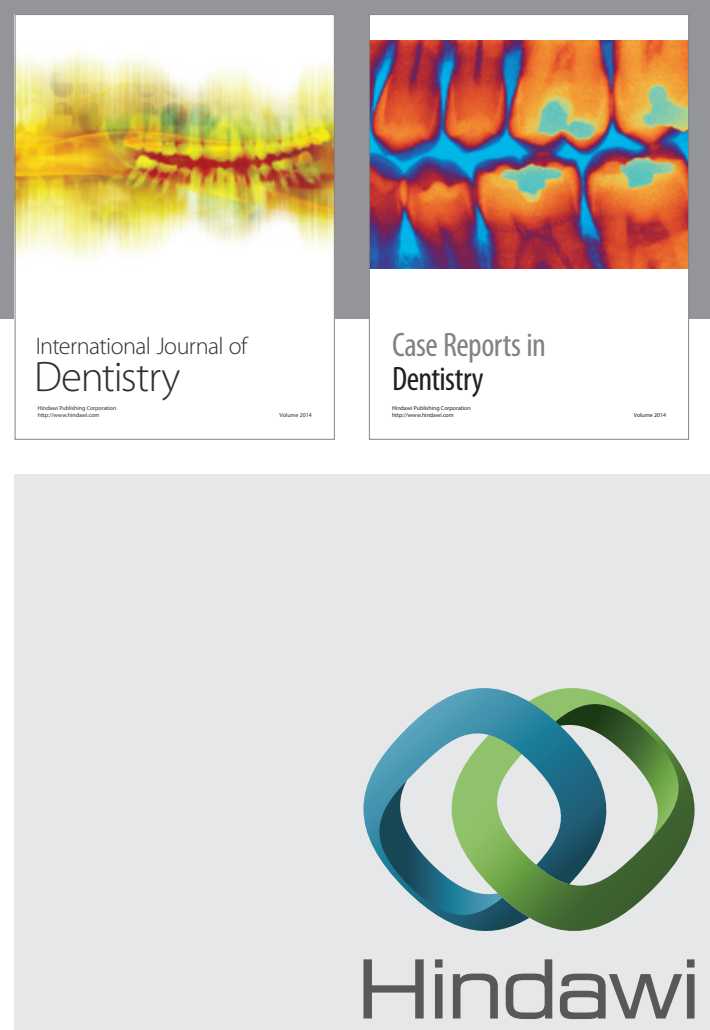

Submit your manuscripts at

http://www.hindawi.com
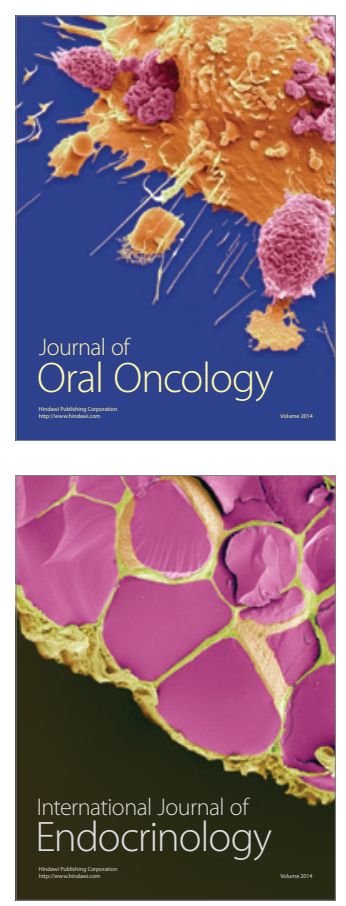
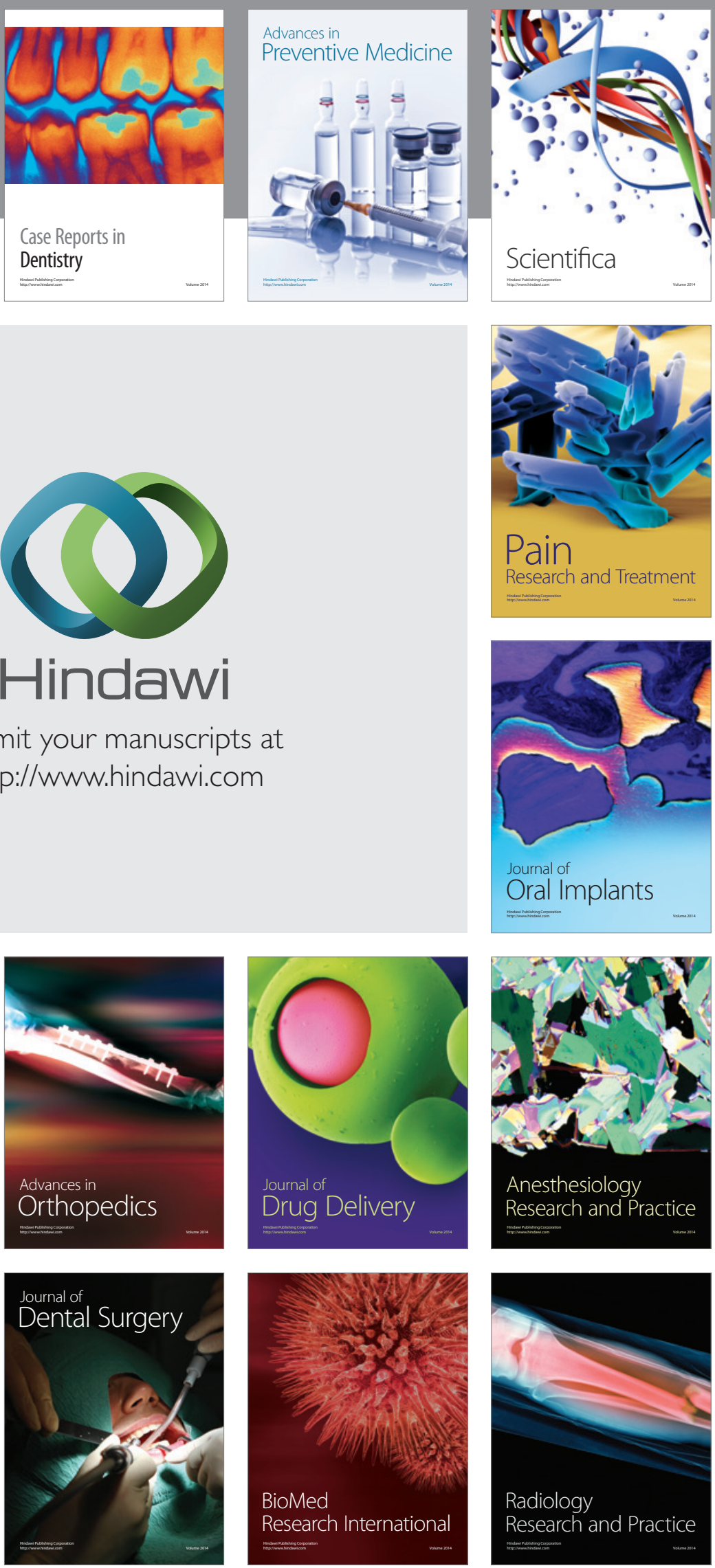